\title{
Overwhelming bone marrow Leishmaniasis
}

\author{
Kemik iliğinde yoğun Leishmaniasis
}

\author{
Raihan Sajid, Adnan Qureshi \\ Department of Pathology and Microbiology, Aga Khan University, Karachi, Pakistan
}

Visceral Leishmaniasis (kala-azar) is caused by the intracellular parasitic organism Leishmania donovani and is transmitted by the bite of an infected sandfly Phlebotomus argentipes. Clinical manifestations of advanced disease usually include constitutional symptoms, such as prolonged fever, anorexia, weight loss, and marked enlargement of the spleen and liver, with varying degrees of pancytopenia [1].

Pakistan is a tropical country situated in the north-west region of South Asia; all of its neighboring countries are endemic for Leishmaniasis, including China, Afghanistan, Iran, and India [2-4]. Leishmaniasis was first reported from Pakistan in 1960 [5]. Initially, it was limited to the northern mountainous region, but currently it is widespread throughout the country with several endemic foci of varying climatic and geographic conditions [6].

Herein we present a 22-year-old female from Hyderabad, Sindh Province, Pakistan that was referred to our laboratory for bone marrow exanimation due to pyrexia of unknown origin. She had fever with chills and rigors that began 2 months earlier, which did not respond to treatment with antimalarials and multiple antibiotics. At presentation she had massive splenomegaly and marked pallor. Complete blood count showed the following: pancytopenia with hypochromic microcytic anemia; hemoglobin: $7.1 \mathrm{~g} / \mathrm{dL}$; hematocrit: $21.8 \%$; MCV: 72.5 fL; MCH: 23.8 pg; MCHC: 29.7\%; total white cell count: $1.5 \times 10^{9} / \mathrm{L}$; absolute neutrophil count: $0.4 \times 10^{9} / \mathrm{L}$; platelet count: $48 \times 10^{9} / \mathrm{L}$. Peripheral blood smear did not show a leukoerythroblastic reaction or the presence of abnormal cells. Bone marrow examination showed hypercellular marrow and massive infestation with the amastigote form of Leishmania donovani in the bone marrow macrophages and in some granulocytes. Written informed consent was obtained from the patient.

The visceral form of Leishmaniasis can be fatal if not treated in a timely fashion and stibogluconate (sodium antimony gluconate) is the drug of choice. Recently, other agents have become available for the treatment of new and resistant cases of visceral Leishmaniasis, including pentamidine isethionate, amphotericin B, miltefosine, and paramomycin [1]. The presented patient received anti-leishmanial treatment with sodium antimony gluconate $20 \mathrm{mg} /$ $\mathrm{kg} / \mathrm{d}$ for $14 \mathrm{~d}$. She began to exhibit improvement within $3 \mathrm{~d}$ and was clinically cured after the full course of therapy. She was last followed-up 1 month after completion of the treatment and was asymptomatic and healthy.

\section{Conflict of interest statement}

The authors of this paper have no conflicts of interest, including specific financial interests, relationships, and/or affiliations relevant to the subject matter or materials included. 


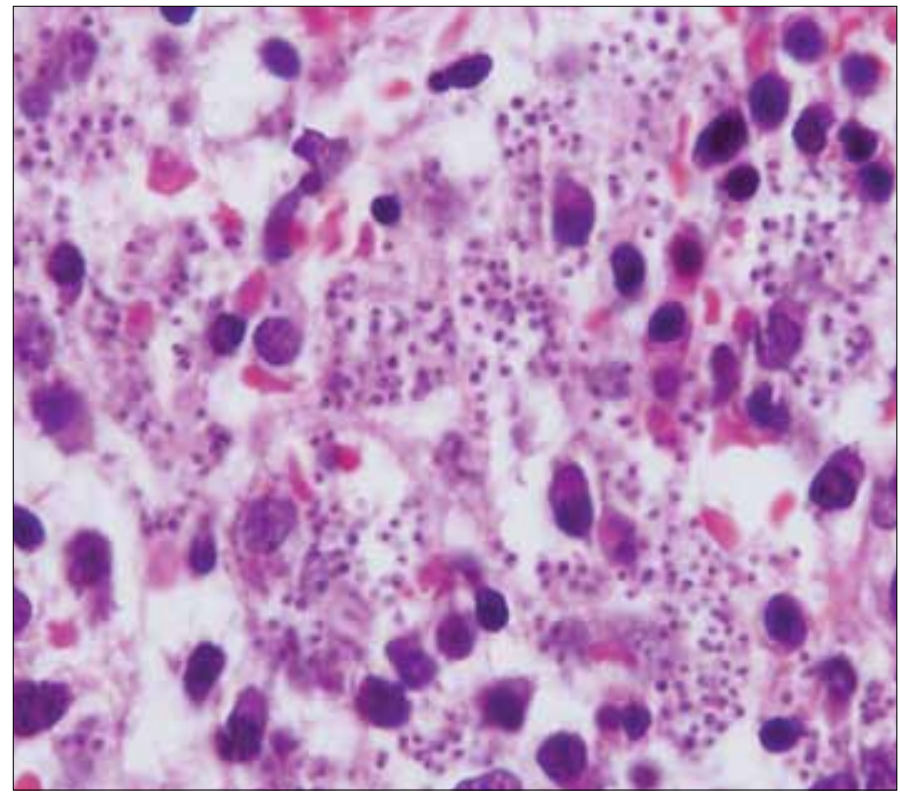

Figure 1. Visceral Leishmaniasis

\section{References}

1. Bhattacharya SK, Sur D, Karbwang J. Childhood visceral Leishmaniasis. Indian J Med Res. 2006;123:353-6.

2. Hewitt S, Reyburn H, Ashford R, Rowland M. Anthroponotic cutaneous Leishmaniasis in Kabul, Afghanistan: vertical distribution of cases in apartment blocks. Trans Roy Soc Trop Med Hyg 1998;92:273-4. [CrossRef]

3. Dogra J. Cutaneous Leishmaniasis in India: Evaluation of oral drugs (dapsone vs itraconazole). Eur J Dermatol 1992;2:568-9.

4. Momeni AZ. Amin Javaheri M. Clinical picture of cutaneous Leishmaniasis in Isphahan, Iran. Int J Dermatol 1994;33:260-5. [CrossRef]

5. Ahmad N, Burney MI, Wazir Y. A preliminary report on the study of kalaazar in Baltistan (West Pakistan). Pak Arm Force Med J 1960;10:1-10.

6. Yasnzai MM, Iqbal J, Kakar JK et al. Leishmaniasis in Pakistan: revisited. J Coll Physicians Surg Pak 1996;6:70-5. 